\title{
Current distribution measurements in a PEFC with net flow geometry
}

\author{
M. NOPONEN ${ }^{1}$, J. IHONEN ${ }^{2}$, A. LUNDBLAD ${ }^{2}$ and G. LINDBERGH ${ }^{2} *$ \\ ${ }^{1}$ Laboratory of Advanced Energy Systems, Helsinki University of Technology, PO Box 2200, FIN-02015 HUT, \\ Finland \\ ${ }^{2}$ Department of Chemical Engineering and Technology, Applied Electrochemistry, Royal Institute of Technology, \\ S-10044, Stockholm, Sweden \\ (*author for correspondence, fax: +468108 087, e-mail: goeran.lindbergh@ket.kth.se)
}

Received 16 June 2003; accepted 6 October 2003

Key words: current distribution, net flow geometry, PEFC, segmented current collector

\begin{abstract}
A measurement system for current distribution mapping for a PEFC has been developed. The segmented anode is constructed so as to have high thermal conductivity in order to prevent the formation of large temperature gradients between the electrodes. The construction is therefore feasible for use at high current densities. Both segmented and unsegmented gas diffusion layers are used. The effect of inlet humidification and gas composition at the cathode side is studied. In addition, two different flow geometries are studied. The results show that the measurement system is able to distinguish between current distribution originating from differences in proton conductivity, species concentration and gas diffusion layer properties.
\end{abstract}

\section{Introduction}

Polymer electrolyte fuel cells (PEFCs) are currently being introduced into the market in small stationary power production units and in portable power units for consumer electronics. PEFCs are also seen as an alternative to internal combustion engines in passenger vehicles and such applications are already in service. PEFC systems for these applications are still too expensive to gain a significant market share but on the other hand the cost expectations make PEFC an attractive future option for these markets [1,2].

At ambient pressure, the highest performance is achieved at around $80^{\circ} \mathrm{C}$ mainly due to decreased ionic resistance and enhanced electrochemical activity. Under these conditions optimal cell and stack designs become increasingly important since high air stoichiometries are required to compensate for the dilution of air by water vapour [3]. Uniform distributions of current, temperature, concentration of reactants and water are beneficial not only to produce maximum power densities but also to ensure maximum lifetime for the cell components. In the development of optimal stack designs, fluid dynamic and electrochemical modelling is an invaluable tool. Since the fuel cell performance is defined as a sum of many complex variables, a reliable mathematical model is very difficult to construct. Some of the recent models as well as reviews of previous ones can be found in references [4-6]. To ensure that the modelling results predict the performance of a real PEFC accurately, the models should be verified by measurements. Measurement of the current distribution is one important verification method.

Current distribution measurements have been used not only in PEFC research [7-14] but also as a tool to study local current production in electrolytic processes [15-25] and direct methanol fuel cells (DMFCs) [26-29]. The use of a segmented current collector in PEFC research is, however, a much more complicated issue compared to the other processes because of high heat production rates and low heat capacity of the reactant and the product gases. Thus, the heat rejection takes place mainly through the current collectors. This can cause a problem especially when the printed circuit board approach is used because the thermal conductivity of the polymer materials used is usually orders of magnitude lower than with conventional current collectors. Therefore, heat in these structures is expected to be taken mostly from the unsegmented side of the cell, and thus the measured current distributions might not correspond to an unsegmented PEFC.

In addition to the current distribution measurements, other local cell phenomena can be studied experimentally. These include the local concentration [30], impedance [31] and probe measurements [32-35], and neutron imaging [36-38]. In this paper, the development of a segmented current collector based on stainless steel for current distribution measurements in a PEFC is described and results of the first measurements are reported for two different flow geometries. Additionally, 
problem areas in the net flow field design are identified and discussed.

\section{Experimental details}

The measurement system includes a fuel cell with a segmented current collector, a system for gas and water control, and a potentiostat and data logging system. A detailed description of the fuel cell used with an unsegmented structure and the measurement system are presented in [39]. In Figure 1, the structure of the fuel cell with segmented structure is schematically illustrated. The cell material is stainless steel 316 if not otherwise stated.

The cell used in the measurements has three different compartments: the segmented anode, the unsegmented cathode and the water circulation chamber behind both the anode and cathode compartments for cell temperature control. The segmented anode side consists of a back plate ( $f$ in Figure 1A), a segmented current collector ( $e$ in Figure 1A) and a segmented flow field, that is, platinum-plated stainless steel net pieces, $(d$ in Figure 1A). The back plate has a similar geometry for gas feeding as the current collector in the symmetrical case at the cathode side (Figure 1B).

The current collector at the anode was segmented into 4 rows and 8 columns. While the active area of the cell was $60 \mathrm{~mm} \times 90 \mathrm{~mm}$, the segmentation resulted in approximately $1.7 \mathrm{~cm}^{2}$ areas for each segment. A $1.2 \mathrm{~mm}$ thick copper wire was attached at the back side of each current collector piece. The current wires had a thin polymer coating in order to ensure that no electrical
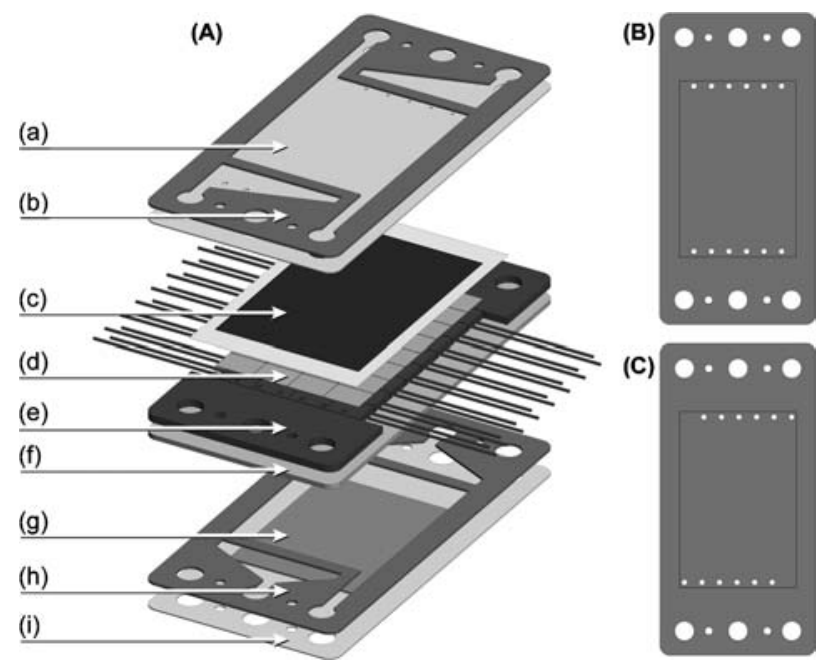

Fig. 1. (A) Structure of the segmented cell: (a) current collector, (b) gasket, (c) MEA with gas diffusion layers, (d) segmented flow field, (e) segmented current collector, (f) backplate for the segmented current collector, (g) flow field for water, (h) gasket and (i) endplate. Anode and cathode gaskets and flow net at the cathode side are not illustrated. (B) Current collector with symmetrical flow field. (C) Current collector with asymmetrical flow field. Active area is illustrated with a black square in (B) and (C). contact could be established between the inner and outer segments.

An insulating, but thermally conductive, tape (type 9890 by $3 \mathrm{M}^{\mathrm{TM}}$ ) was placed between the back plate and the current collector pieces. A $0.5 \mathrm{~mm}$ gap was left between each segment to ensure that no electrical contact could be established between the segments. The gaps were filled with epoxy (Epofix from Struers Inc.) to ensure a gastight structure. It was observed that the structure bent during the hardening of epoxy and small gas leakage paths were emerged into the junction of the epoxy and the metal. The leakage was measured to be $0.1-0.2 \mathrm{~cm}^{3} \mathrm{~s}^{-1}$ when the cell was pressurized up to 200 mbar. The segmented current collector structure was finished by plating it with platinum, which caused $30 \pm 10 \Omega$ electric contacts between the segments. The current leakage through these contacts is, however, negligible.

Each current wire was soldered onto a mechanical switch. The other side pole was connected to a copper plate and the other was kept unconnected. The use of switches enabled the study of a desirable number of segments at a time. The resistances between the segments and the copper plate were measured using the four point method and they varied between $6-8 \mathrm{~m} \Omega$.

The flow fields at the anode ( $d$ in Figure 1A) and cathode were made of platinum plated stainless steel nets. The thickness of the net was $0.48 \mathrm{~mm}$ and the material was SS2343 from Weisse \& Eschrich GmbH \& Co. KG. At the anode side, the net was cut into 32 pieces, which were glued from their edges onto the segmented current collector with adhesive tape (Scotch ${ }^{\top \mathrm{M}}$ $467 \mathrm{MP}$ by $3 \mathrm{M}^{\mathrm{TM}}$ ).

The gas diffusion layers on both sides were $\mathrm{Carbel}^{\mathrm{TM}}$ CL gas diffusion media from W. L. Gore \& Associates. The in-plane electric conductivity for this material was measured with four point method to be about $50 \mathrm{~S} \mathrm{~cm}^{-1}$. At the anode side, both segmented and unsegmented gas diffusion layer structures were used. When the segmented structure was used, the carbon cloth pieces were glued on the segmented net with $3 \mathrm{M}$ adhesive from the edges of the pieces. The gap between the adjacent gas diffusion layers was less than $0.5 \mathrm{~mm}$ and resistance between the segments remained the same as was the case without the gas diffusion layers.

The MEA ( $c$ in Figure 1A) used in the measurements was Primea ${ }^{\circledR} 5510$ with $0.3 \mathrm{mg}(\mathrm{Pt}) \mathrm{cm}^{-2}$ loading at both sides (W. L. Gore \& Associates) and it was unsegmented in all measurements. Electric conductivity is typically in a range of $1-5 \mathrm{~S} \mathrm{~cm}^{-1}$ for the MEA surface [40]. The gaskets at the anode and cathode side were $0.6 \mathrm{~mm}$ thick silicon rubber combined with $0.13 \mathrm{~mm}$ thick glass fibre reinforced PTFE sealings.

At the cathode side two different flow geometries were studied. In both cases, there were six gas inlet and outlet holes and a platinum plated stainless steel net served as the flow medium. The difference between the geometries was the placement of the gas inlets and outlets. In the symmetrical case (Figure 1B), the spacing of the gas 
inlet holes was $9 \mathrm{~mm}$ and the gas outlet holes were placed on the same horizontal line at a distance of $85 \mathrm{~mm}$. In the asymmetrical case (Figure 1C), the spacing and horizontal distance of the holes were the same but there was a $10 \mathrm{~mm}$ displacement between the adjacent inlet and outlet holes.

The temperature of the fuel cell was controlled by means of a water circulation system. Water was directed between the cathode side endplate and the current collector ( $a$ in Figure 1A) and between the anode side endplate ( $i$ in Figure 1A) and the segmented structure. The flow media for water were gold plated stainless steel nets similar to the flow media at the anode and cathode sides. The gaskets at the water parts were $0.5 \mathrm{~mm}$ thick Grafoil $^{\circledR}$ sheets. The endplates were $8 \mathrm{~mm}$ thick stainless steel plates having dimensions of $120 \mathrm{~mm} \times$ $160 \mathrm{~mm}$. The cell was compressed between the endplates with ten $6 \mathrm{~mm}$ thick bolts.

Before the fuel cell tests, the clamping pressure distribution on the MEA was studied with a Pressurex ${ }^{\circledR}$ film from Fujifilm, since the clamping pressure has been noticed to have a significant effect on the flooding of the gas diffusion layers, on the thermal resistance and on the contact resistances [41]. In these experiments, the cell was assembled placing a Pressurex ${ }^{\circledR}$ film (Ultra Low) instead of an MEA. The results showed that the middle part of the active area was less compressed than the edges, and thus an additional clamping screw was attached to the middle of the cell.

In the fuel cell tests, pure hydrogen $(99.999 \%$ from Aga AB) was used at the anode and synthetic air or oxygen with the same purity at the cathode. The flow rates were controlled using Brooks 5858S mass flow controllers. Both at the cathode and anode side two flow controllers were used to control the flow rates to enable high precision control. The smaller flow range at the cathode was between $0-500 \mathrm{~cm}^{3} \mathrm{~min}^{-1}$ and the larger between $500-2600 \mathrm{~cm}^{3} \mathrm{~min}^{-1}$, and at the anode side between $0-540 \mathrm{~cm}^{3} \mathrm{~min}^{-1}$ and $540-1950 \mathrm{~cm}^{3} \mathrm{~min}^{-1}$. The accuracy of all of these controllers was $1 \%$ of their maximum flow rate. At the anode side, the stoichiometry was kept at 3.4 in the symmetric flow field case and at 2.7 in the asymmetric case. At the cathode side, the air stoichiometry was 1.3 and oxygen stoichiometry 5.5 in the symmetric flow field case, and 1.1 in the asymmetric case. The anode flow rates at the given stoichiometries and cell conditions were found to have an insignificant effect on the current distributions.

Reactant gases were led through a humidifier substation made by GlobeTech. The dew point temperature for hydrogen was kept at $60{ }^{\circ} \mathrm{C}$ in the measurements. At the cathode side, measurements were conducted with two different dew points, $40{ }^{\circ} \mathrm{C}$ stated as the low and $60{ }^{\circ} \mathrm{C}$ as the high humidity level. In order to ensure that the humidified gases did not condense before entering the cell, gas pipes were heated to $70^{\circ} \mathrm{C}$. All measurements were conducted at atmospheric pressure conditions. The pressure drop in the cell at maximum flows was measured to be about 100 mbar at the segmented anode side and 200 mbar at the cathode side.

The external water circulation system used for the cell temperature control consisted of a water pump, heater, flow controller and water filter. The cell was vertically oriented so that the water flowed upwards while the gases flowed downwards, in a co-flow manner. Cell temperature could be controlled by measuring the inlet and outlet water temperature. Average value for these was kept at $60^{\circ} \mathrm{C}$ in the measurements. At the maximum heat production rates, water was heated from 59 to $61{ }^{\circ} \mathrm{C}$.

The total current of the cell was controlled with an EL 300 electronic load interfaced to a potentiostat (IM6, Zahner-elektrik GmbH \& Co. KG). With this system it is possible to conduct current interruption and a.c. impedance measurements. The current interruption technique was used to determine the total resistance of the cell, while a.c. impedance was used to study the resistance of each segment.

The segment currents were determined by measuring the potential drop in each current wire against the copper terminal plate. The measurements were conducted with a 34908A $40 \mathrm{ch}$ Single-Ended Mux module of a 34970A data acquisition switch unit from Agilent Technologies. The data logger was PC controlled with Agilent BenchLink Data Logger software via GPIB. It was observed that the resistance over the mechanical switches changed over time and therefore they were frequently calibrated. The resulting error for the measured currents was determined to be $1-2 \%$. In addition, nonzero currents were measured at the open circuit potential and these varied typically between -20 and $20 \mathrm{~mA} \mathrm{~cm}^{-2}$. A possible reason for this could be small reactant leakages between the anode and cathode creating current loops inside the cell. However, this behaviour was found to be negligible at high current densities.

The electrochemical performance was studied for each individual segment. These measurements were performed in order to detect malfunctioning segments and to study the possible reason for decreased performance. Measurements were conducted at a constant current level, $760 \mathrm{~mA} \mathrm{~cm}{ }^{-2}$, having only one segment connected at a time letting all current produced in the cell flow through that segment. The virtual resistance of each segment was determined from the high frequency, $1 \mathrm{kHz}$, a.c. impedance. At the cathode, oxygen at a dew point of $67^{\circ} \mathrm{C}$ was used with a stoichiometry of 2 . These measurements were conducted with the unsegmented gas diffusion layer design.

Current distribution measurements were conducted in galvanostatic mode. The cell was operated at each current level for 20-30 min and the last $10 \mathrm{~min}$ were used for the current distribution measurements. Before changing the current level the cell resistance was measured using the current interruption method. A PULSE analysis module of the THALES software package was used to analyse the current interruption data. Details of this module can be found in [42]. 


\section{Results and discussion}

\subsection{Effect of gas diffusion layer segmentation}

The need for gas diffusion layer segmentation arises from its smoothing effect on current distribution. Segmentation is needed especially if segment specific resistances are not equal. The segment resistances were measured by switching on one segment at a time. The segment specific resistances are depicted in Figure 2. There were four segments, the segments $(1,4),(3,4),(7,2)$ and $(8,4)$, that had higher resistance than the others. This was due to poorer contacts between the current wires and the segments than for the other segments. The segment $(3,4)$ was found to be the most problematic in our calibration measurements and it was therefore short circuited to the segment $(3,3)$. In the current distributions, an average current density value has been used for these segments.

Another remarkable feature in Figure 2 is that the segments at the edges have a slightly higher resistance than those in the middle. The segments at the edges also had worse performance than segments in the middle. Since the gas diffusion layer on the anode side and the whole cathode side of the cell are not segmented, the effective area for one current collector segment is larger than its geometrical area. In the middle this effect is larger than at the edges. Thus, the method is not accurate to study segment resistances quantitatively. However, it has shown to be effective to study the reasons for malfunctioning segments (e.g., if the reason is higher resistance or gas leakage).

The segmentation of a gas diffusion layer should not significantly change the hydrogen concentration profile when pure humidified hydrogen is used. Thus, the disturbing effect on current distribution on the anode side should be minor. To study the possible benefits of a segmented gas diffusion layer, a measurement series was conducted. However, when measurements were done at high current densities $\left(\sim 1 \mathrm{~A} \mathrm{~cm}^{-2}\right)$, the MEA was found

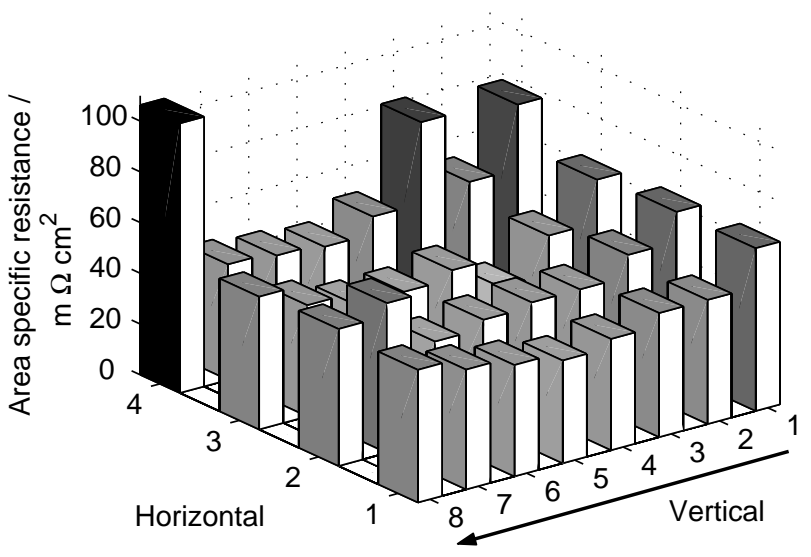

Fig. 2. Segment specific resistances. Arrow shows flow direction of reactant gases. to break down from the places where there was poor mechanical support (i.e., from the edges of the gas diffusion layer segment). A lack of support results in high thermal impedance and thus in overheating of the MEA thereby reducing its lifetime. After it was noticed that the MEA could not endure the gas diffusion layer segmentation, only unsegmented gas diffusion layers were used. This would therefore mean that the real current distribution at the electrode is somewhat more pronounced than the measured quantities because of the current smoothing, as discussed in [43].

\subsection{Current distribution studies for symmetric flow field}

The current distribution studies were conducted to examine: (i) how well the performance of the segmented cell corresponds to the unsegmented one; (ii) how the uneven segment resistances affect the current distribution; (iii) how the low inlet humidity affects the current distribution; (iv) how the reduced partial pressure of oxygen affects the current distribution; and (v) how the reduced partial pressure of oxygen and the low inlet humidity affects the current distribution.

The effect of the segmentation and uneven segment resistances were studied with pure oxygen at a high inlet humidity level. When pure oxygen is used, the mass transfer resistance should be negligible at high stoichiometries. In addition, the high humidity level ensures that the resistance distribution should be negligible.

The current distribution measured with oxygen at the high humidity level is depicted in Figure 3(a). When these results are compared to the segment specific resistance distribution (Figure 2) it can be seen that the differences in current distribution are almost solely due to different segment resistances. In addition to the resistance effects, some minor differences can be observed in the regions where gases entered and left the active area (rows 1 and 8) as seen from Figure 3(b). These entrance and outlet effects are most likely formed because of 'dead-zones' behind the inlet and outlet holes. The flow velocity is much smaller in these areas compared to the area between the inlet and outlet holes, thus creating reduced oxygen concentration and current densities at these regions. This effect is also present when pure oxygen is used since insufficient water removal may lead to flooding of the flow field. The effect may also be partly due to slightly worse cooling of the edge segments because the cooling area ( $g$ in Figure 1 ) only covers the first and last segment rows partially.

The polarization behaviour of the segmented cell (Figure 3(c)) was compared to previous experiments conducted with a similar unsegmented cell [44]. The segmentation had only a small, if any, effect on the cell performance.

The effect of the low humidity level was studied using pure oxygen. The results are depicted in Figure 4. The current density increases towards the outlet (Figure 4(a) and (b)). The water produced in the cathode reaction increased the humidity level of the gas streams, and 
(a)

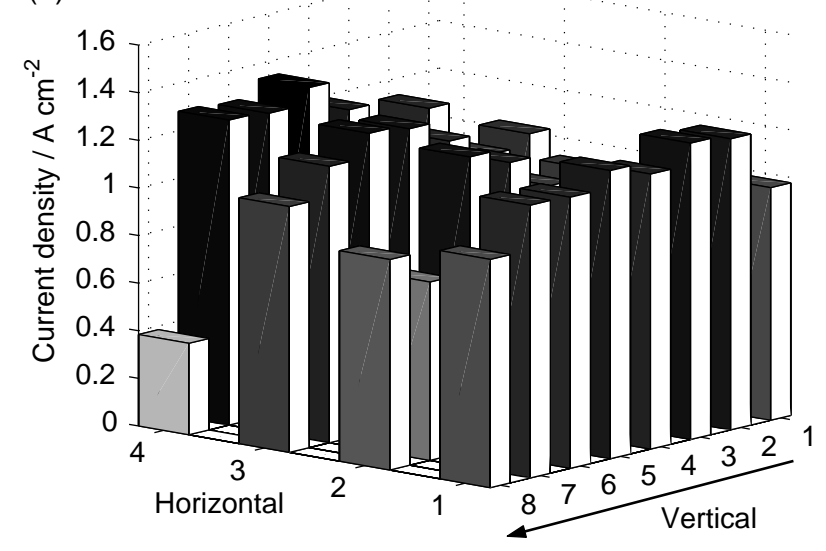

(b)

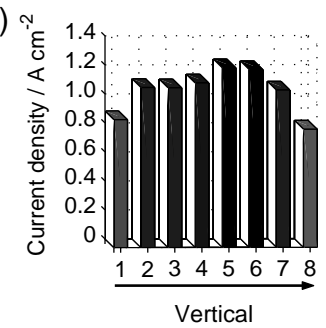

(c)

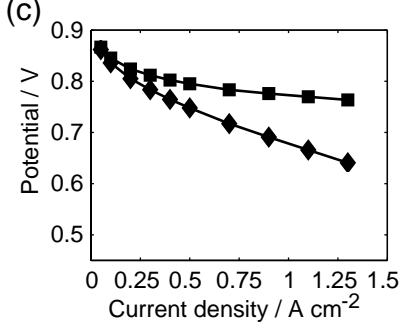

Fig. 3. (a) Current distribution measured with oxygen and high humidity; (b) horizontally averaged current distribution; (c) measured cell potential ( ) and iR-corrected cell potential (ם). Arrows express flow direction of reactants. Stoichiometry: 5.5 for oxygen and 3.4 for hydrogen; average current density in (a) and (b): $1.1 \mathrm{~A} \mathrm{~cm}^{-2}$.

improved proton conduction was achieved at the end. The current distribution would have been somewhat smoother at the outlet if the segment $(8,4)$ had not been malfunctioning. The cell performance, depicted in Figure 4(c), shows clearly that the polarization behaviour did not change significantly compared to the measurement conducted with the high humidity level.

The effect of reduced partial pressure of oxygen was studied using air at a fairly low stoichiometric flow rate and the high humidity. The results are depicted in Figure 5. The effect of increased mass transfer resistance is clearly seen from Figure 5(a) and (b). More current is produced near the inlet because of the higher oxygen partial pressure. Mass transfer problems can also be observed from Figure 5(c), where the performance decrease is evident compared to measurements conducted with pure oxygen.

The combined effect of the reduced oxygen partial pressure and the reduced humidity level is depicted in Figure 6. The current distribution depicted in Figure 6(a) is now divaricated. At the edges the current distribution follows the pattern of the measurement conducted with air and high humidity while the middle part follows the pattern of oxygen and low humidity level.

The behaviour in the middle parts of the cell was as expected. The effects from MEA humidity level differences are evident (i.e., an increasing trend from the inlet) and from the mass transfer resistance effects (i.e., a

(a)

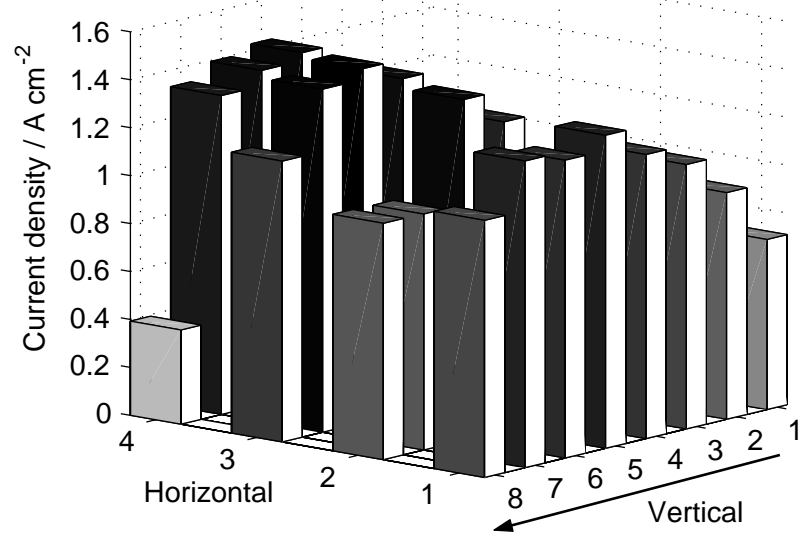

(b)
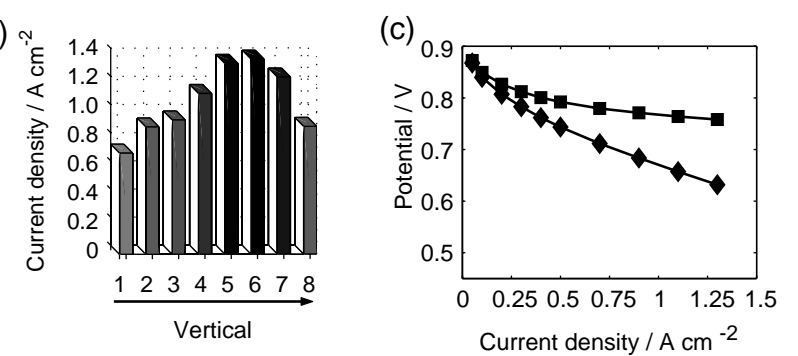

Fig. 4. (a) Current distribution measured with oxygen and low humidity; (b) horizontally averaged current distribution; (c) measured cell potential $(\checkmark)$ and iR-corrected cell potential (⿴). Arrows express flow direction of reactants. Stoichiometry: 5.5 for oxygen and 3.4 for hydrogen; average current density in (a) and (b): $1.1 \mathrm{~A} \mathrm{~cm}^{-2}$.

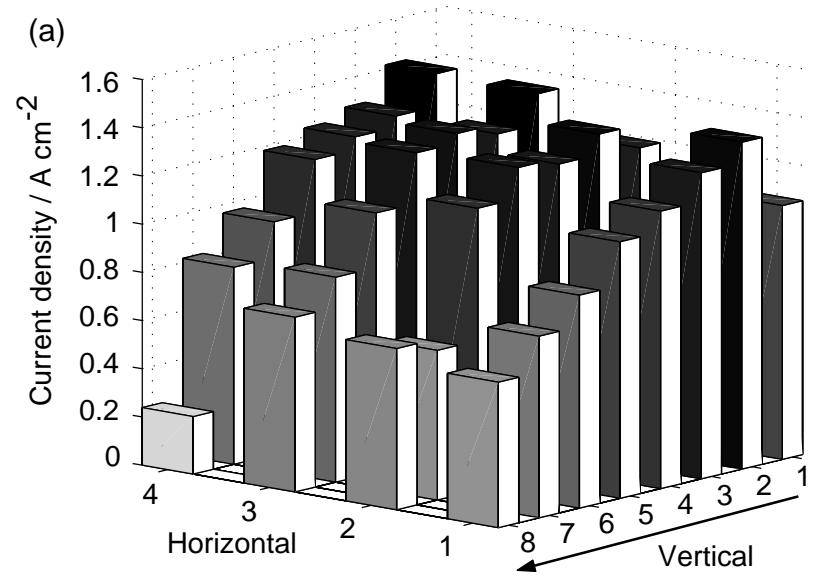

(b)
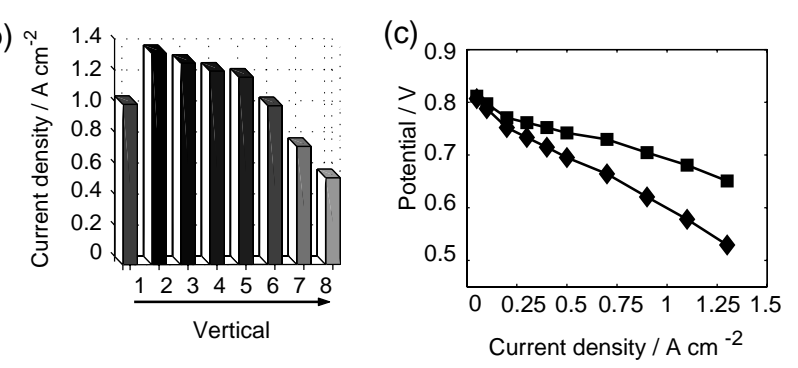

Fig. 5. (a) Current distribution measured with air and high humidity; (b) horizontally averaged current distribution; (c) measured cell potential ( ) and iR-corrected cell potential (₫). Arrows express flow direction of reactants. Stoichiometry: 1.3 for air and 3.4 for hydrogen; average current density in (a) and (b): $1.1 \mathrm{~A} \mathrm{~cm}^{-2}$. 


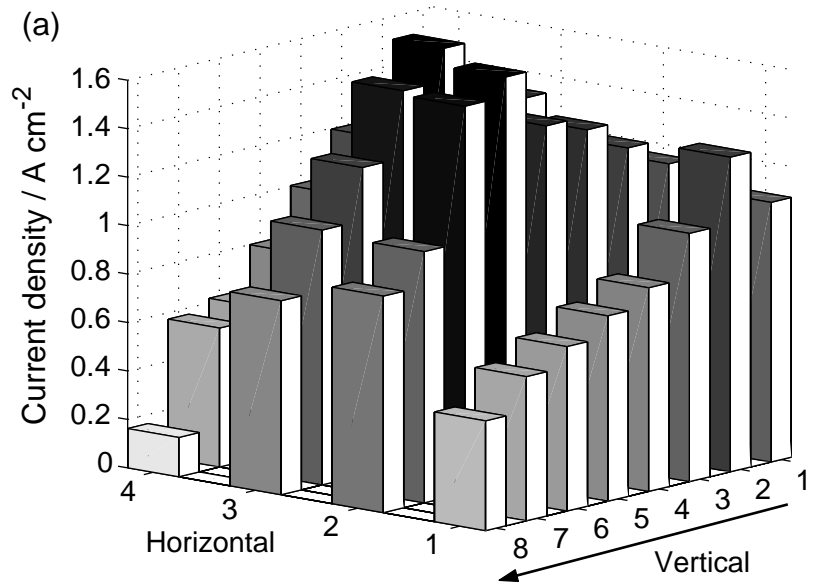

(b)

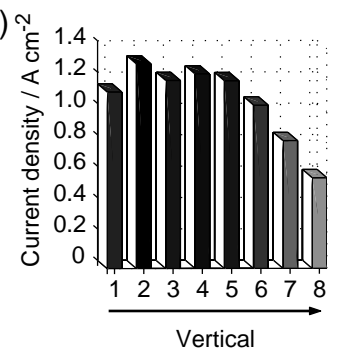

(c)

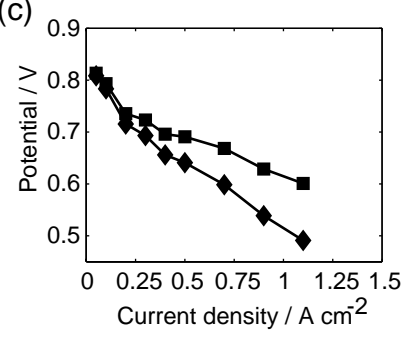

Fig. 6. (a) Current distribution measured with air and low humidity; (b) horizontally averaged current distribution; (c) measured cell potential $(\diamond)$ and iR-corrected cell potential $(\mathbf{\square})$. Arrows express flow direction of reactants. Stoichiometry: 1.3 for air and 3.4 for hydrogen; average current density in (a) and (b): $1.1 \mathrm{~A} \mathrm{~cm}^{-2}$.

decreasing trend towards the outlet). The behaviour at the edge parts is more complicated. Even though the additional clamping screw was placed in the middle part of the cell, the compression level at the edges was somewhat larger than in the middle parts. Therefore, it is likely that the permeability is lower at the edges than in the middle. Hence, the airflow is also decreased in the gas flow field (i.e., both in the net and gas diffusion layer). This results in increased mass transport resistance for oxygen and water. Thus, proton conduction is increased at the edges but the mass transfer problems are pronounced.

The horizontally averaged current distribution, depicted in Figure 6(b), deviates significantly from Figure 6(a). In the previous cases (Figures 3-5), the averaged and nonaveraged current distributions were comparable. The advantage of the previous cases was that they can be used as PEFC model validation tools because a two dimensional model is sufficient to explain the cell behaviour. Here, however, the use of averaged current for the model verification would be questionable.

\subsection{Current distribution studies for asymmetric flow field}

In the stack presented in reference [39], the inlet and outlet holes for reactant gases were placed asymmetrically to the current collector plate to enable an easy gasket structure. Within this study, a measurement was

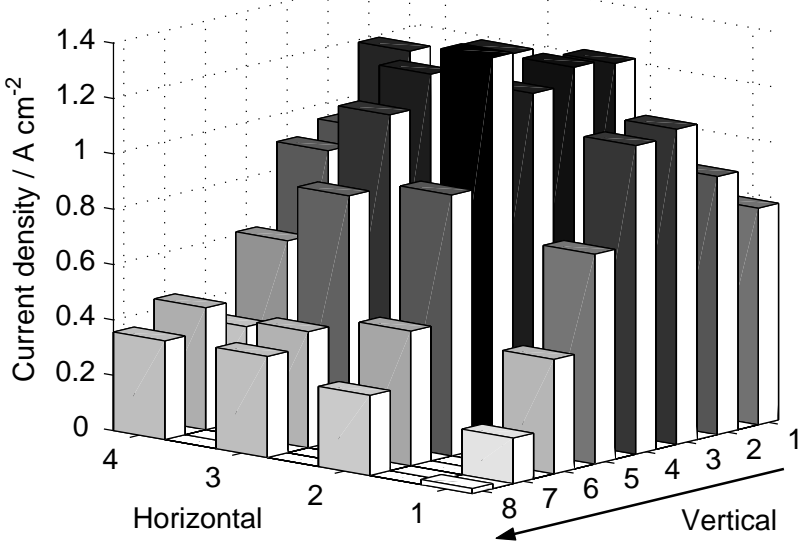

Fig. 7. Current distribution measured with air and low humidity in asymmetric flow field case. Arrows express flow direction of reactants. Stoichiometry: 1.1 for air and 2.7 for hydrogen: average current density: $0.5 \mathrm{~A} \mathrm{~cm}^{-2}$; cell voltage: $0.57 \mathrm{~V}$.

also performed in order to study if this asymmetric structure resulted in undesirable current distribution. An asymmetrical current collector (Figure 1C) was placed at the cathode side while the anode structure was the same as was used in the previous measurements. The stoichiometry at the cathode was only 1.1, since the lowest possible stoichiometry was studied for stack development purposes. At the anode the stoichiometry was 2.7. In this measurement, the dew points were $46^{\circ} \mathrm{C}$ and $56^{\circ} \mathrm{C}$ for cathode and anode gas flows in order to avoid flooding. Measurement was conducted at one current level $\left(500 \mathrm{~mA} \mathrm{~cm}^{-2}\right)$ for $60 \mathrm{~min}$ and the final 20 min period was used for recording the current distribution. The result is depicted in Figure 7.

It can be seen that the corner where the segment $(8,1)$ is located produced almost no current. This corner has no outlet hole for the cathode exhaust gas. Therefore, the air velocity in this corner is much lower compared to other regions and a barrier for oxygen transfer is formed. A similar behaviour can be observed at the adjacent inlet corner $(1,4)$, which correspondingly did not contain an inlet hole. The mass transfer resistance is, however, much smaller because the partial pressure of oxygen around the inlet was significantly higher than around the outlet. The experiment was repeated with pure oxygen but with otherwise similar conditions. Similar behaviour was not observed and thus no flooding problems could create the 'dead-zone' effect.

\section{Conclusions}

A current distribution measurement system feasible for high power density fuel cell studies has been presented. The polarization behaviour of the segmented cell is comparable to an unsegmented one. The cell proved to be usable for current distribution measurements even though the resistances of the segments were not totally 
uniform. The current distribution in net flow geometry was studied by varying the inlet humidification and the partial pressure of the oxygen at the cathode side. With these measurements it was shown that the system is capable of detecting differences in ionic conductivity and mass transfer properties. It was also noticed that the uneven clamping pressure had a significant effect on the local cell performance.

The measurement system was furthermore used to investigate current distribution on an asymmetrical net flow field for the cathode side. The asymmetric structure resulted in an unfavorable current distribution near the outlet.

The gas diffusion layer was not segmented at the anode side in the measurements. This might have resulted in current smoothing and distorted resistance distribution. Therefore, a measurement series was conducted with a segmented gas diffusion layer. However, it was noticed that the MEA required better mechanical support than the segmented gas diffusion layer could provide and the insufficient mechanical support led to rapid degradation of the MEA at high current densities.

Our future aim is to develop the segmented cell so that it can be used as a verification tool for fuel cell models. Special attention to the cell structure will be focused on obtaining one dimensional current distribution profiles (i.e., current distribution along the gas flow). That is, only two dimensions are needed for modelling the cell, thus reducing the calculation time. To achieve one dimensional current distribution the gas inlet and outlet effects, as well as differences in the clamping pressures, have to be avoided. In addition, the measurement system can be used to study different flow field geometries for the cathode side.

\section{Acknowledgements}

The financial support of the Swedish Foundation for Strategic Environmental Research (MISTRA), the Nordic Energy Research (NEFP) and the Jenny ja Antti Wihurin Rahasto are gratefully acknowledged.

\section{References}

1. Arthur D. Little Inc., 'Cost analysis of fuel cell system for transportation: Baseline system cost estimate', US Department of Energy, Report SFAA, no. DE-SCO2-98EE50526 (2001).

2. D. Oei, J. A. Adams, A.A. Kinnelly, G.H. Purnell, R.I. Sims, M.S. Sulek, D.A. Wernette, B. James, F. Lomax, G. Baum, S. Thomas and I. Kuhn, 'Direct hydrogen fueled proton exchange membrane fuel cell system for transportation applications', Final Technical Report Report DOE/CE/50389-505, Ford Motor Company (2000).

3. R.K.A.M. Mallant, J. Power Sources 118 (2003) 424.

4. J.S. Yi and T.V. Nguyen, J. Electrochem. Soc. 146 (1999) 38.

5. N. Djilali and D. Lu, Int. J. Therm. Sci. 41 (2002) 29.

6. G.J.M. Janssen, J. Electrochem. Soc. 148 (2001) A1313.

7. D.J.L. Brett, S. Atkins, N.P. Brandon, V. Vesovic, N. Vasileiadis and A.R. Kucernak, Electrochem. Commun. 3 (2001) 628.
8. S.J.C. Cleghorn, C.R. Derouin, M.S. Wilson and S. Gottesfeld, J. Appl. Electrochem. 28 (1998) 663.

9. M.M. Mench, C.Y. Wang and M. Ishikawa, J. Electrochem. Soc. 150 (2003) A 1052.

10. M. Noponen, T. Mennola, M. Mikkola, T. Hottinen and P. Lund, J. Power Sources 106 (2002) 304.

11. N. Rajalakshmi, M. Raja and K.S. Dhathathreyan, J. Power Sources 112 (2002) 331.

12. J. Stumper, S.A. Campbell, D.P. Wilkinson, M.C. Johnson and M. Davis, Electrochim. Acta 43 (1998) 3773.

13. Ch. Wieser, A. Helmbold and E. Gülzow, J. Appl. Electrochem. 30 (2000) 803.

14. Y-G. Yoon, W-Y. Lee, T-H. Yang, G-G. Park and C-S. Kim, J. Power Sources 118 (2003) 193.

15. J.M. Bisang, J. Appl. Electrochem. 21 (1991) 760.

16. C.J. Brown, D. Pletcher, F.C. Walsh, J.K. Hammond and D. Robinson, J. Appl. Electrochem. 22 (1992) 613.

17. P. Byrne, 'Mathematical modelling and experimental simulation of chlorate and chlor-alkali cells', Dissertation, Royal Institute of Technology, Stockholm, Sweden (2001).

18. M. Chikhi, M. Rakib, Ph. Viers, S. Laborie, A. Hita and G. Durand, Desalination 149 (2002) 375.

19. L.R. Czarnetzki and L.J.J. Janssen, J. Appl. Electrochem. 19 (1989) 630.

20. L.J.J. Janssen and G.J. Visser, J. Appl. Electrochem. 21 (1991) 753.

21. L.J.J. Janssen and G.J. Visser, J. Appl. Electrochem. 21 (1991) 386.

22. K. Onda, T. Murakami, T. Hikosaka, M. Kobayashi, R. Notu and K. Ito, J. Electrochem. Soc. 149 (2002) A1069.

23. J. Qi and R.F. Savinell, J. Appl. Electrochem. 20 (1990) 885.

24. H. Riegel, J. Mitrovic and K. Stephan, J. Appl. Electrochem. 28 (1998) 10

25. K. Scott, W. Taama and B.R. Williams, J. Appl. Electrochem. 28 (1998) 259.

26. E. Gülzow, T. Kaz, R. Reissner, H. Sander, L. Schilling and M. Bradke, J. Power Sources 105 (2002) 261.

27. R. Liu and E. S. Smotkin, J. Electroanal. Chem. 535 (2002) 49.

28. M.M. Mench and C.Y. Wang, J. Electrochem. Soc. 150 (2003) A79.

29. N. Wagner, T. Knöri, E. Gülzov and C.A. Schiller, Abstracts of 53rd Annual Meeting of International Society of Electrochemistry, Dusseldorf, Germany 15-20 Sept. (2002), p. 298.

30. M-M. Mench, Q-L. Dong and C-Y. Wang, J. Power Sources 124 (2003) 90

31. D.J.L. Brett, S. Atkins, N.P. Brandon, V. Vesovic, N. Vasileiadis and A. Kucernak, Electrochem. Solid-State Lett. 6 (2003) A63.

32. F.N. Büchi and G.G. Scherer, PSI Scientific Report V (1998), p. 57.

33. J-N. Han, G-G. Park, Y-G. Yoon, T-H. Yang, W-Y. Lee and C-S. Kim, Int. J. Hydrogen Energy 28 (2003) 609.

34. P.J.S. Vie, 'Characterisation and optimisation of the polymer electrolyte fuel cell', Dissertation, NTNU, Trondheim, Norway (2002).

35. M. Watanabe, H. Igarashi, H. Uchida and F. Hirasawa, J. Electroanal. Chem. 399 (1995) 239.

36. R.J. Bellows, M.Y. Lin, M. Arif, A.K. Thompson and D. Jacobson, J. Electrochem. Soc. 146 (1999) 1099.

37. A.B. Geiger, A. Tsukada, E. Lehmann, P. Vontobel, A. Wokaun and G.G. Scherer, Fuel Cells 2 (2002) 92.

38. A. Tsukada, E. Lehmann, P. Vontobel and G.G. Scherer, PSI Scientific Report V (1999) p. 84.

39. J. Ihonen, J. Xu, S. Schwartz, A. Lundblad, G. Lindbergh and C. Kaijser, 'PEFC stack based on stainless steel net flow fields' to be submitted to J. Power Sources.

40. P. Gode, F. Jaouen, G. Lindbergh, A. Lundblad and G. Sundholm, 'Influence of the composition on the structure and electrochemical characteristics of the PEFC cathode' Electrochim. Acta, in press.

41. J. Ihonen, M. Mikkola and G. Lindbergh, 'The flooding of gas diffusion backing in polymer electrolyte fuel cells; Physical and 
electrochemical characterization', to be submitted to J. Electrochem. Soc.

42. F. Richter, C-A. Schiller and N. Wagner, 'Current interrupt technique - Measuring low impedances at high frequencies' in Electrochem. Applications 1 (2002), Editor: Hans-Joachim Schäfer, Zahner-elektrik GmbH \& Co. KG, Kronach.
43. M. Noponen, T. Hottinen, T. Mennola, M. Mikkola and P. Lund, J. Appl. Electrochem. 32 (2002) 1081.

44. D. Tamm, 'Influence of anode gas composition on polymer electrolyte fuel cell (PEFC) performance', MSc thesis, Royal Institute of Technology, Stockholm, Sweden (2002). 